\title{
Family veto in organ donation in Canada: framing within English-language newspaper articles
}

\author{
Samantha J. Anthony PhD MSW, Maeghan Toews LLM, Timothy Caulfield LLM, \\ Linda Wright MHSc MSW
}

\section{Abstract}

Background: Because organ transplantation relies on public support for donation, an analysis of public discourse around organ donation is essential. We investigated the portrayal of family veto - when a family overrides the deceased person's prior legally executed wishes to donate - in Canadian news media.

Methods: Using the Canadian Newsstream database, we identified articles published in English-language newspapers addressing family veto between 2000 and 2016. Guided by the theoretical perspectives of framing of media effects, we conducted a systematic content analysis of the articles to examine how the Canadian media framed family veto. An initial in-depth analysis of the data set in which themes and patterns were captured and recorded identified coding categories, including primary framing of family veto, prevalence, reasons, ethical or legal concerns and overall tone of the article. Two coders analyzed the data set to ensure intercoder reliability.

Results: A total of 133 relevant articles were identified. Family veto was framed predominantly as something that should not be allowed (81 articles [60.9\%]) and as a reality that is little understood outside the transplantation community (45 [33.8\%]). One-quarter of the articles (32 [24.1\%]) highlighted ethical principles of autonomy and justice associated with family veto. Family veto was represented as a stumbling block in the present organ donation system, with most publications (107 [80.4\%]) calling for change. There were differing interpretations of organ donation legislation, with 82 articles (61.6\%) erroneously stating or suggesting that existing legislation permits family veto.

Interpretation: Family veto in organ donation was portrayed predominantly negatively. Many publications reflected a misunderstanding of the law concerning this issue. Although the framing of family veto highlighted important ethical and legal concerns as well as practice and policy considerations, research is needed to enhance the understanding of family veto in organ donation.

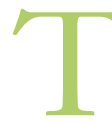
ransplantation is a cost-effective, life-saving therapy for many patients with end-organ failure, but transplantable organs are in short supply. Almost 4500 Canadians are currently on transplantation waiting lists. As wait lists continue to grow, patients suffer prolonged illness, and some die waiting for a donor. ${ }^{1}$ Organ transplantation relies on public support and willingness to donate. The public gains much of their knowledge about health and scientific developments from the popular press. ${ }^{2-4}$ Research has shown that how an issue is framed in the media can affect public discourse and shape public opinion and policy debates. $^{2-10}$

Canadians can communicate their wish to be an organ donor by documenting it in writing. ${ }^{11}$ In some jurisdictions, one can also join a donor registry. ${ }^{12-15}$ Although this authorization is legally sufficient for organ procurement after death, it is common practice to seek agreement from the person's next-of-kin before donation proceeds. ${ }^{16}$ When a family member of a person who has given legal consent to donate decides against donation, this is referred to as family veto. The veto represents a conflict between respect for the deceased person's previously expressed wishes and those of the family. How family veto is framed in the media can affect public discourse on organ donation. The aim of our research was to investigate the portrayal of family veto in organ donation in Canadian newspapers and identify the major frames surrounding family veto that have featured most prominently in discourse in the print media.

Competing interests: Linda Wright is Cochair, Bioethics Advisory Group, Trillium Gift of Life Network, and a member of the Bioethics Advisory Committee, Canadian Blood Services. No other competing interests were declared.

This article has been peer reviewed.

Correspondence to: Samantha Anthony, samantha.anthony@ sickkids.ca CMAJ Open 2017. DOI:10.9778/cmajo.20170051 


\section{Methods}

The Canadian Newsstream (formerly Canadian Newsstand Complete) database (via ProQuest Web interface) offers access to the full text of nearly 300 newspapers from Canada's leading publishers. We searched this database for Englishlanguage print articles addressing family veto between Jan. 1, 2000 and Dec. 31, 2016. The database review was guided by a search strategy developed in collaboration with a medical research librarian that included the following terms: (famil* or wife or husband or child* or mother or father or daughter* or son*) or (next of kin) AND veto* or challenged* or overrule* or over-rule* or overturn* or over-turn* or override* or override* $^{*}$ or dispute* or oppose* AND (organ* NEAR/2 (donor* or donation $\left.{ }^{*}\right)$ ) or $\left(\right.$ kidney $^{*}$ NEAR/2 (organ* or donation*)) or (liver* NEAR/2 (donor* or donation*)) or (heart* NEAR/2 $\left(\right.$ donor $^{*}$ or donation $\left.{ }^{*}\right)$ ) or (lung* NEAR/2 (donor* ${ }^{*}$ or donation*). Duplicate and topically irrelevant articles in which there was no mention of family veto in organ donation were removed from the data set.

A framing paradigm provides a conceptual process within which to analyze the influence of the media on public discourse. Framing theory emphasizes the selective presentation of specific topics, facts, controversies and assertions in media coverage. ${ }^{10,17-19}$ Guided by the theoretical perspectives of framing of media effects, we conducted a systematic content analysis of the newspaper articles to examine how the Canadian media framed family veto in organ donation. An initial in-depth analysis of the data set in which themes and patterns were captured and recorded identified coding categories. The coding categories were also informed by the theoretical per- spectives of framing as well as the experience and knowledge of the research team. We defined all analytic categories in a structured coding framework with the following variables: 1) frequencies of coverage by newspaper and province, 2) publication date, article type, author or article source, and who was attributed with providing information or evidence on family veto, 3 ) identification of the primary framing of family veto in organ donation, 4) prevalence of family veto, 5) reasons for family veto, 6) ethical or legal concerns with family veto, 7) whether the article made recommendations and 8 ) the overall tone (positive, neutral, negative) of the article.

Two coders (S.A. and a research assistant) analyzed the data set to ensure intercoder reliability. One researcher coded the complete data set, and the other independently coded a random selection of 61 articles ( $45.9 \%$ of the total). We measured intercoder variability using the $\kappa$ statistic. Calculation of the $\kappa$ statistic is based on the difference between how much agreement is actually present (observed) compared to how much agreement would be expected by chance alone (expected). The $\mathrm{K}$ scores for the coding frame categories ranged from 0.60 to 1.00 , indicating moderate to excellent intercoder reliability. ${ }^{20}$ The $\kappa$ score was greater than 0.74 for $80 \%$ of the coding questions; the scores for the analytical categories of frame and tone were 0.76 and 0.74 , respectively. We used NVivo 10 software for management of qualitative data.

\section{Ethics approval}

Because the study involved a media analysis and did not involve human participants, research ethics approval was not required at our academic institutions.

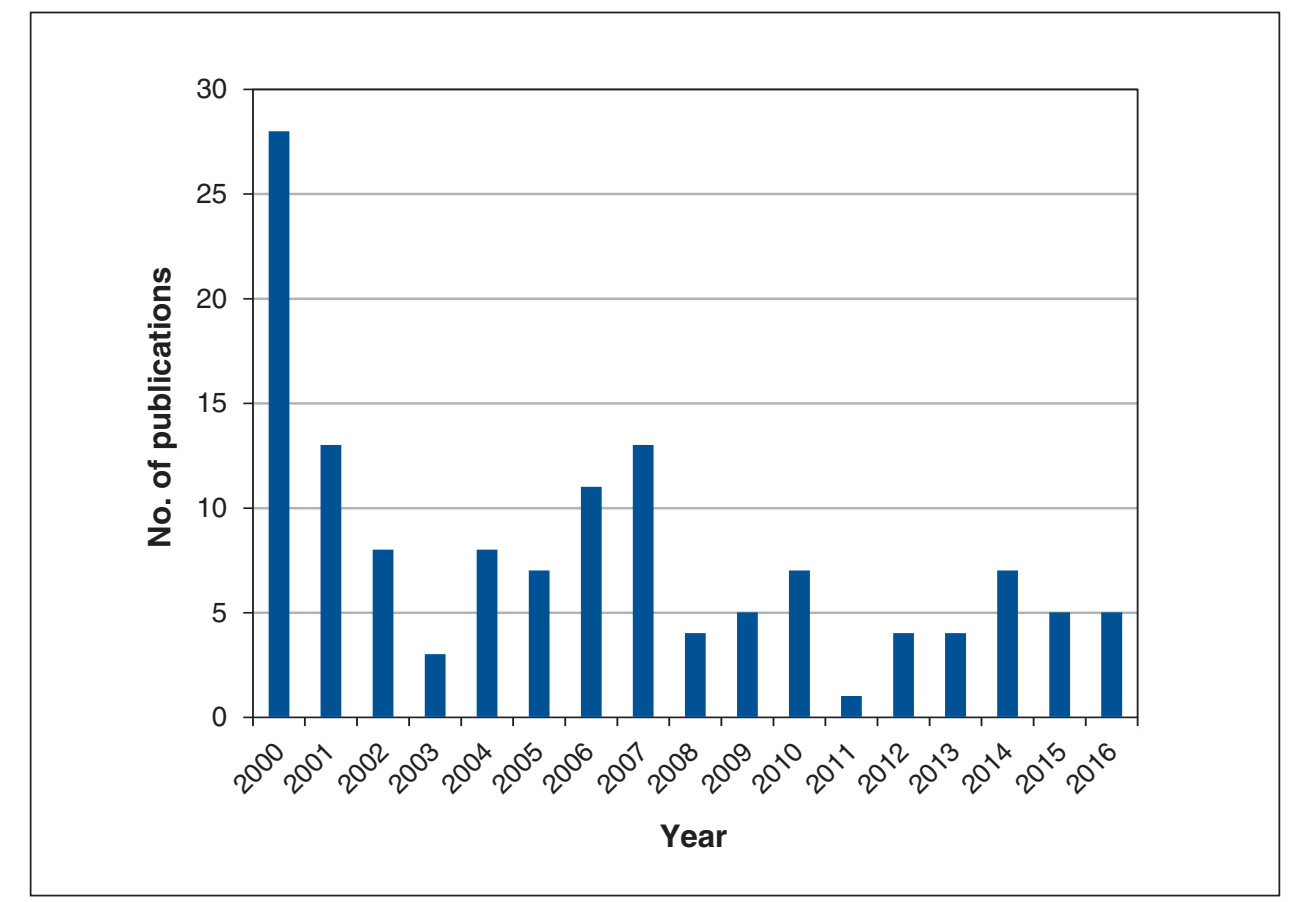

Figure 1: Distribution of print articles addressing family veto published in English in Canada, Jan. 1, 2000, to Dec. 31, 2016. 


\section{Results}

The search of the Canadian Newsstream database yielded 695 articles. After duplicate $(n=117)$ and topically irrelevant (e.g., obituaries, community events, $n=445$ ) articles were excluded, the final data set contained 133 newspaper articles, most of which (94 [71.7\%]) were published in Ontario. Figure 1 shows the distribution of the publications over the study period. Peaks in distribution reflect activities related to campaigns aimed at raising awareness about organ donation, the release of public survey data and proposed legislative changes. The highest number of articles (22 [16.5\%]) were published in the Ottawa Citizen, followed by the Toronto Star (11 [8.3\%]). The former is a daily newspaper with an average print readership of 208000 distributed in Canada's capital..$^{21}$ The Toronto Star is Canada's largest daily newspaper, with the largest readership in the country, 999000 in the Greater Toronto Area on an average weekday. ${ }^{22}$

Of the 133 articles, 41 (30.8\%) were published in the news section of newspapers, $12(9.0 \%)$ in the health or lifestyles section, and $5(3.8 \%)$ on the front page. Most of the articles (85 [63.9\%]) were categorized as news stories. Editorials or opinion pieces and letters were also prominent types of articles included in the sample (30 articles [22.6\%]). Nearly half of the articles (61 [45.9\%]) were written by journalists: 30 $(22.6 \%)$ by staff writers, $22(16.5 \%)$ by columnists and 9 $(6.8 \%)$ by science/health writers. Five journalists authored 2 articles, and 1 journalist authored 3 articles; the remaining 120 articles were authored by different journalists.

\section{Primary framing of family veto}

We identified 2 major frames in the portrayal of family veto in organ donation. It was predominantly framed as "something that should not be allowed to occur" in 81 articles $(60.9 \%)$ (Box 1). The concept of a family's overriding a deceased person's expressed wish to donate was characterized as "terribly wrong," "a shame" and "tragic."

Family veto was also framed as a reality that is little understood outside the transplantation community (45 articles [33.8\%]). Publications conveyed the perspective that Canadians may think that, by signing an organ donor card or expressing their wishes through an online registry, their intentions will be honoured. However, when made aware of the issue of family veto through newspaper publications, people expressed "dismay," "surprise," "bitterness" and "anger" in editorials, opinion pieces and letters: "What a shock to read that anyone - even if it is my next-of-kin - has the power to veto my wishes to donate organs after my death." There was frustration that it is simply not enough to sign an organ donor card or register one's wishes: "I carry an organ donor card, but it's absolutely no use." A common theme in one-third of the articles (45 [33.8\%]) was the need to bring attention to the reality of family veto.

\section{Prevalence of family veto}

Fifteen articles $(11.3 \%)$ referenced the prevalence of family veto. Among these articles, there was wide variance in the cited occurrence of family veto, ranging from $5 \%$ to $70 \%$.
Information about prevalence rates was primarily attributed to quotes from family members and/or patients, patient advocates and health care professionals.

\section{Reasons for family veto}

Forty articles (30.1\%) addressed reasons for family veto. The deceased person's not having previously discussed his or her decision with family members was the predominant reason (28 articles [21.0\%]): "So many people don't realize their family members' wishes;" "If you sign your organ donor card and your family is unaware of your wishes, they may reverse that decision." Other reasons highlighted included 1) "custom" and "culture" of the hospital ("It's custom — not the law, not ethics and not public opinion - to ask the family;" "Asking the family is part of the folklore, part of the culture of the intensive care unit," 2) the family is approached at a difficult time ("We're approaching the family at a weak moment;" "They're in shock and not able to make decisions," 3) health care workers are concerned about being sued ("Doctors are afraid if they remove organs without the family's consent they will be sued") and 4) hospital staff do not wish to further harm the family ("No hospital staff would agree to operate on a patient if they knew the family did not consent;" "We really don't want to agitate people") and wish to "avoid the awkward issue altogether."

Box 1: Quotes illustrating primary frame: family veto should not be allowed

"A family shouldn't be able to override a person's decision to donate organs at the time of death if they signed a card. That is like saying a dead person's will is not valid and a family can disperse belongings as they wish."

"Loved ones should not be able to overrule signed intentions to donate."

"Something is terribly wrong when the wishes of the deceased are respected in disposing of their possessions but are ignored when their bodies are the issue."

"When you just have 1 person who didn't have his wishes come true, that's 1 person too many."

"The family should not have a veto vote on this informed decision."

"Family should not be able to overrule organ donations.... Individual donors, not their family members, should have the final say on organ donation."

"The law, public opinion and ethics all support an individual's right to have [his or her] decision honoured."

"Opinion polls show that better than 90 percent of Canadians don't want family views to outweigh their own."

"We have a tradition [of] respecting people's last will and testament. ... Why do we so easily deny them their last will about what happens to their body parts after they die - what could be more personal?"

"While [the family's] reluctance is understandable, organ donation is not and should not be their decision to make. A signed donor card or its electronic equivalent should be treated as a sacrosanct commitment made by one who has died so that one may live."

"Opting to keep or donate organs should be a decision that cannot be overturned by family." 
In 12 articles (9.0\%), the author questioned who is responsible for the occurrence of family veto. The publications were divided between placing responsibility on families (6 [4.5\%]) ("The family can overrule ... which is an act of extreme selfishness") and physicians (5 [3.8\%]) ("Doctors are driving down the donor rate by not agreeing to a donor's wishes"). One letter to the editor implied that the responsibility should be directed at the government.

\section{Ethical or legal concerns}

One-quarter of the articles (32 [24.1\%]) highlighted ethical issues associated with family veto. These concerns were centred on the ethical principles of autonomy and justice. Ethical issues surrounding family veto were framed as "infringing" or "violating" individual rights, patient values and personal autonomy. These articles emphasized that one's personal choice in matters of organ donation should be "respected" and "honoured."

Almost two-thirds of the articles (82 [61.6\%]) erroneously stated or implied that existing legislation permits fam-

\section{Box 2: Representations of legislation}

\section{Legislation permits family veto}

"Under Ontario law, even if a donation card has been signed, family members could overrule the donor's wishes when death occurs."

"The government needs to change a legislative provision that allows family members to overturn permission to harvest organs. That can occur despite the fact that an individual has signed the necessary documents."

"In Ontario, it is the law that we approach the family and obtain consent."

"Without regulations prohibiting families from stepping in and halting the organ donation process, all health authorities can do is watch helplessly as another person's chance at life might be abruptly ended."

"Officials ... still require permission from the deceased's next-of-kin." "The legislation will fall short because it continues to allow the family to overrule the desire of a relative to donate."

"Right now, in every province, officials must approach families to make the final decision on organ and tissue donations."

\section{Legislation prohibits family veto}

"Seeking the family's agreement violates the Human Tissue Gift Act in each province."

"Signing an organ donor card means you've given 'full and binding consent' to donating parts of your body, and a doctor who asks your family for permission is breaking the law."

"It is only a matter of time before an institution is sued [by someone awaiting an organ] for failing to follow the relevant laws."

"Family members cannot legally defy a loved one's willingness to donate unless they have good reason. Organ donors' wishes must be legally honoured after death, except when a family can prove the donor changed his or her mind after signing up."

"People have suggested we should change the law, but the law we have would work very well if we used it. We should not be asking the next-of-kin when we have a fully binding law right now." "Ontario legislation states clearly that you have every right to specify whether your organs can be donated after your death. You - no one else - have the final say." ily veto, whereas only a handful of articles (13 [9.8\%]) suggested that family veto is not permitted by existing legislation (Box 2).

\section{Recommendations}

Most articles (107 [80.4\%]) expressed concerns about the present organ donation system and offered recommendations to address the issue of family veto: "The organ donation system as it exists is seriously flawed;" "Much can be done to improve the system." Family veto was viewed as "an all too frequent reality that medical authorities would love to see changed." Recommendations included 1) the need for people who wish to donate their organs to talk to family members and make their wishes known (62 articles [46.6\%]), 2) the need for campaigns to promote organ donation awareness (22 [16.5\%]), 3) an "opt-out" or "presumed consent" system (21 [15.8\%]) and 4) legislative changes to ensure that potential donors' decisions are respected $(16[12.0 \%])$. Those cited in support of recommendations to address family veto included family members and/or patients (23 [17.3\%]), patient advocates $(17$ [12.8\%]), academic or scientific experts (16 [12.0\%]) and health care professionals (11 [8.3\%]).

\section{Tone of coverage}

News coverage was primarily negative, with over half of the articles (77 [57.9\%]) opposing family veto. Fifty-six articles $(42.1 \%)$, including 49 providing descriptive coverage and 7 presenting positive and negative and/or multiple perspectives, framed family veto in a neutral manner. None of the articles portrayed family veto in a primarily supportive or positive manner.

\section{Interpretation}

In this media discourse analysis, family veto was portrayed predominantly negatively; not 1 article framed it in a positive manner. It was largely framed as something that should not be allowed. Among articles that referenced the prevalence rate of family veto, there was wide variance, ranging from $5 \%-70 \%$. According to the Trillium Gift of Life Network, Ontario's organ and tissue donation agency, 31 families $(22 \%)$ of registered donors declined in 2012/13, 26 (15\%) in 2013/14 and 39 (18\%) in 2014/15 (Janice Beitel, Director, Hospital Programs, Education and Professional Practice, Trillium Gift of Life Network: personal communication, 2015).

The ethical issues associated with family veto highlighted in the articles were framed around the principle of autonomy. One-quarter of the articles stressed the importance of respect for the autonomous wishes of the deceased person. This is in line with the concept that society has a duty to enable the wishes of a person who has taken the time to register his or her desire to be an organ donor. Such compliance with the person's wishes is in keeping with the administration of a will for material goods, which does not consider the family's agreement or dissent with the choices made but, rather, rests on the last known capable, legally registered wishes of the deceased person. 
Family veto was represented as a "stumbling block" in the present organ donation system, with most of the publications calling for change. It is striking that almost two-thirds of the articles stated or implied that family veto is permitted under law, as this is incorrect in every Canadian province and territory. ${ }^{16}$ The fact that legislative change to address family veto was recommended in $12 \%$ of the articles further reflects this misunderstanding of the law.

\section{Limitations}

Limitations of this media discourse analysis include a focus on print media and the inclusion of only English-language articles. Future research could explore French-language media coverage as well as a wider range of news media, including broadcast news (radio and television) and the Internet (e.g., news blogs, websites, podcasts). Nevertheless, our focus on English-language print news sources provides an interesting snapshot of how family veto in organ donation is covered by the Canadian press.

\section{Conclusion}

Although there was widespread consistency in the negative tone of print media coverage of family veto, there was great variation in the coverage of details, such as how often family veto occurs, why it occurs and what should be done to address it. This variation may be due to a lack of reliable data and information on these issues. These topics represent important areas for further research that may enhance understanding of family veto in Canada. In particular, research with families who have vetoed their relative's registered wish to donate and with donation professionals who have enforced families' objections in this situation may provide valuable information about why family veto occurs and what response, if any, is warranted. In addition, it would be useful to have greater transparency and consistency between provincial organ donation organizations in terms of quantitative data about how often family veto occurs. This could allow for greater accuracy and consistency in media reporting and serve as a resource of information for the public.

\section{References}

1. Canadian Organ Replacement Register annual report: treatment of end-stage organ failure in Canada, 2002-2011. Ottawa: Canadian Institute for Health Information; 2011.

2. Garrett JM, Bird SJ. Ethical issues in communicating science. Sci Eng Ethics 2000;6:435-42.
3. Holliman R. Media coverage of cloning: a study of media content, production and reception. Public Underst Sci 2004;13:107-30.

4. Nelkin D. Selling science: how the press covers science and technology, revised ed. New York: W.H. Freeman; 1995.

5. Seale C. Health and the media: an overview. Sociol Health Illn 2003;25:513-31.

6. Bubela C, Nesbit MC, Borchelt R, et al. Science communication reconsidered. Nat Biotechnol 2009;27:514-8.

7. Nisbet MC, Mooney C. Science and society. Framing science. Science 2007;316:56.

8. Mazur A. Media coverage and public opinion on scientific controversies. $f$ Commun 1981;31:106-15.

9. Callaghan K, Schnell F. Assessing the democratic debate: how the news media frame elite policy discourse. Polit Commun 2001;18:183-213.

10. Scheufele D. Framing as a theory of media effects. 7 Commun 1999;49:103-22.

11. Downie J, Shea A, Rajotte C. Family override of valid donor consent to postmortem donation: issues in law and practice. Transplant Proc 2008;40:1255-63.

12. Alberta Organ and Tissue Donation Registry. Government of Alberta. Available: https://myhealth.alberta.ca/Pages/OTDRHome.aspx (accessed 2017 Feb. 3).

13. BC Transplant. Register your decision! Vancouver: Provincial Health Services Authority; 2017. Available: https://register.transplant.bc.ca/ (accessed 2017 Feb. 3).

14. Legacy of Life: Nova Scotia Organ and Tissue Donation Program. Halifax: Province of Nova Scotia. Available: www.legacyoflife.ns.ca/ (accessed 2016 Dec. 9).

15. Beadonor.ca. Toronto: Trillium Gift of Life Network. Available: https://beadonor .ca (accessed 2016 Dec. 9)

16. Toews M, Caulfield T. Evaluating the "family veto" of consent for organ donation. CMA7 2016;188:E436-7.

17. Entman R. Framing: toward a clarification of a fractured paradigm. 7 Commun 1993;43:51-8.

18. Scheufele D, Tewksbury D. Framing, agenda setting, and priming: the evolution of three media effects models. 7 Commun 2007;57:9-20.

19. Gamson WA, Modigliani A. Media discourse and public opinion on nuclear power: a constructivist approach. Am 7 Sociol 1989;95:1-37.

20. Landis JR, Koch GG. The measurement of observer agreement for categorical data. Biometrics 1977;33:159-74.

21. Ottawa Citizen readership shows impressive growth. Ottawa Citizen 2016 July 26. Available: http://ottawacitizen.com/news/local-news/postmedia-has -highest-readership-of-all-canadian-newspaper-groups (accessed 2017 Aug. 17).

22. Star remains at top of GTA readership, numbers show. The Star [Toronto] 2016 Apr. 14. Available: https://wwwthestar.com/news/gta/2016/04/14/star-remains -at-top-of-gta-readership-numbers-show.html (accessed 2017 Aug. 17).

Affiliations: Canadian National Transplant Research Program (Anthony, Toews, Caulfield, Wright); The Hospital for Sick Children (Anthony), Toronto, Ont.; Adelaide Law School (Toews), University of Adelaide, Adelaide, Australia; Health Law Institute (Caulfield), University of Alberta, Edmonton, Alta.; Department of Surgery (Wright), University of Toronto, Toronto, Ont.

Contributors: All of the authors contributed substantially to the study conception and design, data acquisition, analysis and interpretation, and drafting and revising of the manuscript, gave final approval of the version to be published and agreed to be accountable for all aspects of the work.

Funding: This study was funded by the Canadian National Transplant Research Program. Maeghan Toews was supported by the James Kreppner Fellowship from Canadian Blood Services.

Supplemental information: For reviewer comments and the original submission of this manuscript, please see www.cmajopen.ca/content/5/4/ E768/suppl/DC1. 